\title{
Acute effects of smoke exposure on airway and systemic inflammation in forest firefighters
}

This article was published in the following Dove Press journal: Journal of Asthma and Allergy

\author{
Niki Gianniou' \\ Charilena Giannakopoulou ${ }^{2}$ \\ Efrossini Dima ${ }^{2}$ \\ Matina Kardara ${ }^{3}$ \\ Paraskevi Katsaounou' \\ Alexandros Tsakatikas ${ }^{4}$ \\ Charis Roussos ${ }^{1-3}$ \\ Nikolaos Koulouris ${ }^{2}$ \\ Nikoletta Rovina ${ }^{2}$ \\ 'Pulmonary and Critical Care \\ Department, Evangelismos Hospital, \\ $\left.{ }^{2}\right|^{\text {st }}$ Department of Pulmonary \\ Medicine, "Sotiria" Hospital; \\ Athens Medical School, "'M. Simos" \\ Laboratories, Department of \\ Critical Care and Pulmonary \\ Services, National and Kapodistrian \\ University of Athens, Athens, ${ }^{4}$ Medical \\ Department, Hellenic Fireforce, \\ Athens, Greece
}

Correspondence: Nikoletta Rovina Ist Department of Pulmonary Medicine, National and Kapodistrian University of Athens, 152 Mesogion Avenue, Athens GR-II527, Greece

$\mathrm{Tel}+302$ II 077633 I 4

Fax +302107239127

Email nikrovina@med.uoa.gr
Introduction: The aim of this study was to assess respiratory health and airway and systemic inflammation in professional forest firefighters post firefighting.

Methods: A total of 60 firefighters who participated in forest firefighting operations in Greece during 2008 were included in the study. A questionnaire consisting of symptoms and exposure, pulmonary function, atopy, bronchial hyperresponsiveness, and markers of inflammation in induced sputum, serum, and bronchoalveolar lavage (BAL) fluid was assessed.

Results: A measurable eosinophilic and neutrophilic inflammation was shown to be induced in the bronchial airways after acute exposure during forest firefighting. This was associated with increased respiratory symptoms from the upper and lower respiratory tract and pulmonary function impairment. Additionally, a measurable systemic inflammatory response was demonstrated. This study showed that acute exposure during forest firefighting significantly augments the intensity of airway and systemic inflammation in relation to the baseline inflammatory background due to chronic exposure.

Conclusion: The repeated acute exposures during firefighting augment the burden of chronic airway and systemic inflammation and may eventually lead to allergic sensitization of the airways and increased incidence of rhinitis and asthma after prolonged exposure.

Keywords: firefighters, acute exposure, airway inflammation, systemic inflammation, allergic sensitization

\section{Introduction}

Professional firefighters have prolonged exposure to smoke and to a complex mixture of particulate matter and irritant gases that are directly inhaled..$^{1,2}$ It is well established that the use of self-contained breathing apparatuses (SCBAs) during firefighting reduces occupational exposure to fire smoke. ${ }^{3}$ However, these devices are often not used, letting exposure be a major concern. Firefighting has been associated with increased respiratory symptoms, ${ }^{4,5}$ acute respiratory obstruction, ${ }^{6-8}$ and, in some occasions, increased bronchial hyperresponsiveness. ${ }^{9,11}$ Furthermore, some studies suggest that smoke inhalation leads to allergic sensitization and airway inflammation. ${ }^{12,13}$ Noteworthy, apart from the local inflammatory responses in the airways, a measurable systemic inflammatory response is also induced. ${ }^{13-16}$ Data from firefighters who participated in the World Trade Center incident clearly revealed an association between the intensity of the exposure and the effect on pulmonary function parameters ${ }^{17}$ and persisting airway hyperresponsiveness. ${ }^{9}{ }^{918}$ Our group has shown an association between the occupational years and the intensity of airway and systemic inflammation. ${ }^{13}$ Furthermore, a positive association has been shown between the number of fires fought in the previous year 
and the presence of bronchial hyperresponsiveness and the risk of irritant-induced asthma. ${ }^{4}$

Few studies have examined the pre- and postexposure airway and systemic inflammation in forest firefighters. The aim of this study was to assess postexposure respiratory health and inflammation in professional firefighters with acute exposure to forest fire smoke.

\section{Methods}

\section{Study population}

We assessed the effect of intensive exposure to fire smoke on airway and systemic inflammation in a group of 60 firefighters who participated in forest firefighting operations for several days continuously.

Firefighters were administered a standardized questionnaire assessing lifetime chronic respiratory conditions, history of tobacco use, history of symptoms during firefighting and during the interval periods, volunteer firefighter status, and lifetime occupational history. Symptom records included cough, wheezing, sputum production, shortness of breath or chest tightness, and shortness of breath while walking, as well as various eye, nose, and throat symptoms.

Each subject attended the laboratory on two separate visits within a week. On visit one (24-48 hours post exposure), blood sampling, reversibility test, and sputum induction were performed. On visit two (at least 48 hours apart visit one), patients underwent methacholine provocation challenge and skin-prick tests. Bronchoscopy was performed in a subgroup of 12 firefighters who volunteered after signing an informed consent.

The same group of firefighters was reassessed off-season, with an interval time between postexposure and off-season measurements of 3 months. All subjects gave informed consent for the participation in the study, which was approved by the ethics committee of "Sotiria" Hospital for Diseases of the Chest.

\section{Reversibility test}

Lung function (forced expiratory volume in 1 second $\left[\mathrm{FEV}_{1}\right]$ / forced vital capacity [FVC]) was measured with a dry wedge spirometer (MasterScreen; Jaeger, Hoechberg, Germany) according to standardized guidelines. ${ }^{19}$ Measurements were always performed by the same technician using the same spirometer. The reversibility test was performed 20 minutes after inhalation of $200 \mu \mathrm{g}$ salbutamol via a metered dose inhaler. Subjects were instructed not to use short-acting bronchodilators for 12 hours and long-acting bronchodilators for 48 hours prior to pulmonary function testing.

\section{Bronchial responsiveness to methacholine}

The subjects were asked to refrain from consuming caffeinecontaining beverages and from using bronchodilator and anti-inflammatory drugs for a minimum of 48 hours before testing. The subjects were seated wearing a nose clip and were instructed to take a slow vital capacity inhalation through the mouthpiece attached to the spirometer. The nebulizer (Pulmo-Aide; DeVilbiss Heathcare Inc., Somerset, PA, USA) was powered by an electric compressor.

Normal saline solution was inhaled first, followed by doubling concentrations of methacholine $(0.625-25 \mathrm{mg} / \mathrm{mL})$ at 5-minute intervals. The $\mathrm{FEV}_{1}$ was measured before and 30,90 , and 180 seconds after each inhalation. The inhalation was discontinued when the $\mathrm{FEV}_{1}$ fell $20 \%$ below the lowest postsaline solution value or when a dose of $25 \mathrm{mg} / \mathrm{mL}$ was reached. The results were expressed as the provocative concentration of methacholine resulting in a $20 \%$ fall in $\mathrm{FEV}_{1}$ (PC20) obtained from the log dose-response curve by linear interpolation. Subjects with a PC20 $<25 \mathrm{mg} / \mathrm{mL}$ were considered to have airway hyperresponsiveness (AHR). ${ }^{20}$

\section{Skin-prick tests}

Atopic status was measured by skin-prick tests using 13 common aeroallergens applied to the forearm. The allergens tested (HAL Allergen Lab B.V., Haarlem, the Netherlands) were house dust mites (Dermatophagoides pteronyssinus and Dermatophagoides farinae), household pets (cat and dog), pollens (mixed grass, olive, mixed weed, and Parietaria judaica) and molds (Alternaria and Aspergillus fumigatus). Histamine and glycerinated saline solution were used as positive and negative controls. A skin-prick test result was considered positive if the mean wheal diameter was at least $3 \mathrm{~mm}$.

\section{Sputum induction and processing}

Sputum was induced by inhalation of hypertonic saline aerosol and processed as described previously. ${ }^{21}$ Briefly, 15 minutes after salbutamol inhalation $(200 \mu \mathrm{g})$, normal saline $0.9 \%$ and then hypertonic saline $(3 \%, 4 \%$, and $5 \%)$ nebulized by an ultrasonic nebulizer (UltraNeb 2000; DeVilbiss Heathcare Inc.) were inhaled for each concentration over a period of 7 minutes. Subjects were encouraged to cough deeply after the 7-minute intervals. All subjects produced an adequate aliquot of sputum that was processed within 2 hours after termination of the induction.

For differential cell counting, we counted 400-500 nonsquamous cells and reported the percentage of eosinophils, neutrophils, macrophages, lymphocytes, and bronchial 
epithelial cells present in the total nonsquamous cell count. Sputum samples containing $>20 \%$ of squamous cells and with cell viability $<70 \%$ were excluded from analysis as indication of poor quality.

Sputum supernatants were stored at $-80^{\circ} \mathrm{C}$ for subsequent assay for interleukin (IL)-4, IL-8, IL-13, TNF- $\alpha$, vascular endothelial growth factor (VEGF), and eosinophil cationic protein (ECP) concentration. ${ }^{22}$

\section{Bronchoscopy}

After local anesthesia of the throat, larynx, and bronchi, which was achieved with $2 \%$ lidocaine, a flexible bronchoscope (BF-1T200; Olympus Corporation, Tokyo, Japan) was introduced into the bronchial tree and gently wedged into the segmental bronchi of the right middle lobe. Bronchoalveolar lavage fluid (BALF) was obtained by instillation and withdrawal of a total amount of $100 \mathrm{~mL}$ normal saline through the working channel. Bronchoalveolar lavage (BAL) was considered technically acceptable if $>40 \%$ of the total normal saline instilled was recovered, and the lavage fluid (except for the first sample) contained few epithelial cells. To optimize cell viability, BALF was kept at $4^{\circ} \mathrm{C}$ until analyzed. The number of cells per milliliter in the recovered BALF was counted with a cytometer on whole BALF specimens stained with trypan blue and also with May-Grünwald for the evaluation of differential cell counts. ${ }^{23}$

\section{Measurement of inflammation biomarkers} IL-8, IL-4, IL-13, TNF- $\alpha$, VEGF, and ECP concentrations were measured in both serum and sputum supernatants.

The concentrations of TNF- $\alpha$, IL-8, IL-13, and IL-4 were determined by enzyme-linked immunosorbent assay (ELISA) using kits purchased from R\&D Systems, Inc. (Minneapolis, MN, USA). The sensitivities of the assays used were 1.6, 3.5, 32,9 , and $10 \mathrm{pg} / \mathrm{mL}$, respectively. ECP was measured using UniCAP ECP kit (Pharmacia Diagnostics, Uppsala, Sweden) with a detection limit of $0.5 \mathrm{ng} / \mathrm{mL}$.

In all cases, the assays were carried out according to the manufacturer's recommendations.

\section{Statistical analysis}

Continuous variables are expressed as mean $\pm \mathrm{SD}$, and categorical variables are expressed as relative frequencies and percentages. Differences in markers of inflammation between time points in the studied group were initially assessed by the Kruskal-Wallis test and if significant by the MannWhitney rank test. Correlations between inflammatory cells and cytokines in sputum, smoking characteristics, or lung function parameters were calculated with Spearman's rank correlation test. Statistical analysis was not influenced by values at the lower limits of detection since the nonparametric tests used were based on ranks of values. A $p$-value of $<0.05$ was considered significant.

\section{Results}

A total of 60 firefighters of mean age $32.4 \pm 5.7$ (mean \pm SD) were included in the study. In all, 52 (87\%) of them were current smokers with a smoking history of $9 \pm 5$ packyears (mean $\pm \mathrm{SD}$ ). The mean duration of occupation was $8 \pm 6$ years (mean $\pm \mathrm{SD}$ ). None of these firefighters was previously diagnosed with asthma, and 1 (2\%) had a previous diagnosis of allergic rhinitis. In all, 23 among $60(38 \%)$ firefighters were atopic (had at least one skinprick test positive to one of the tested antigens). None of the participants were diagnosed with chronic obstructive pulmonary disease, bronchiectasis, or any other chronic condition of the lung.

Respiratory symptoms such as wheezing, cough, chest tightness, sneezing, and expectoration were statistically significantly higher after firefighting as compared to off-season status ( $p=0.028, p=0.03, p=0.02, p<0.001$, and $p=0.006$, respectively; Table 1).

\section{Pulmonary function tests and bronchial hyperresponsiveness}

Pulmonary function and bronchial hyperreactivity off-season and after firefighting are shown in Table 2. Post exposure, there were no significant differences in $\mathrm{FEV}_{1} \%$ predicted and $\mathrm{FVC} \%$ predicted as compared to off-season. However, $\mathrm{FEF}_{25-75 \%}$ predicted and $\mathrm{FEV}_{1} / \mathrm{FVC}$ were statistically significantly reduced post exposure compared to off-season values $(103 \pm 32$ vs $111 \pm 15$ [mean \pm standard error $\{\mathrm{SE}\}], p=0.026$, and $84 \pm 4$ vs $88 \pm 8$ [mean $\pm \mathrm{SE}$ ], $p=0.024$, respectively; Table 2 ). Moreover, a statistically significant increase in total lung capacity (TLC\% predicted; $90 \pm 11$ vs $97 \pm 11$ [mean $\pm \mathrm{SE}$ ], $p=0,029$ ), along

Table I Respiratory symptoms off-season and post exposure

\begin{tabular}{llll}
\hline Symptom & Off-season & Post exposure & p-value \\
\hline Wheezing, n (\%) & $5(9)$ & $20(33)$ & $\mathbf{0 . 0 2 8}$ \\
Cough, n (\%) & $26(44)$ & $43(71)$ & $\mathbf{0 . 0 3}$ \\
Chest tightness, n (\%) & $3(5)$ & $11(18)$ & $\mathbf{0 . 0 2}$ \\
Nocturnal symptoms, n (\%) & $2(3)$ & $4(7)$ & 0.578 \\
Sneezing, n (\%) & $15(25)$ & $30(50)$ & $<\mathbf{0 . 0 0 ~ I ~}$ \\
Expectoration, n (\%) & $10(16)$ & $20(33)$ & $\mathbf{0 . 0 0 6}$
\end{tabular}

Note: Bold represents statistically significant values $(p<0.05)$. 
with statistically significant reduced diffusing lung capacity (KCO\% predicted; $107 \pm 14$ vs $99 \pm 13$ [mean $\pm \mathrm{SE}$ ], $p=0,039$ ), was observed post exposure (Table 2).

No significant difference was observed between the rate of positive bronchial provocation tests off-season and post exposure (6 [13\%] vs 8 [18\%], $p=0.568$, respectively), as well as the provocative dose of methacholine producing a $20 \%$ fall in $\mathrm{FEV}_{1}$ (Table 2).

\section{Markers of inflammation}

The analysis of the sputum samples revealed a significant increase in neutrophils and eosinophils post exposure as compared to off-season $(48 \pm 5 \%$ vs $16 \pm 4 \%$ [mean $\pm \mathrm{SE}$ ], $p=0.035$, and $3 \pm 0.8 \%$ vs $1.8 \pm 0.7 \%$ [mean $\pm \mathrm{SE}$ ], $p=0.05$, respectively; Table 3 ). BAL analysis showed a significantly higher percentage of neutrophils post exposure as compared

Table 2 Pulmonary function test and bronchial hyperresponsiveness off-season and post exposure

\begin{tabular}{llll}
\hline $\begin{array}{l}\text { Functional } \\
\text { parameter }\end{array}$ & Off-season & Post exposure & p-value \\
\hline FEV $\%$ predicted & $108 \pm 13$ & $107 \pm 16$ & 0.796 \\
FVC\% predicted & $107 \pm 14$ & $107 \pm 12$ & 0.760 \\
FEF $_{25-75 \%}$ predicted & $111 \pm 15$ & $103 \pm 32$ & $\mathbf{0 . 0 2 6}$ \\
FEV $/ F V C^{\text {FFV }}$ & $88 \pm 8$ & $84 \pm 4$ & $\mathbf{0 . 0 2 4}$ \\
FRC\% predicted & $96 \pm 20$ & $98 \pm 18$ & 0.637 \\
TLC\% predicted & $90 \pm 11$ & $97 \pm 11$ & $\mathbf{0 . 0 2 9}$ \\
RV\% predicted & $94 \pm 18$ & $97 \pm 25$ & 0.606 \\
KCO\% predicted & $107 \pm 14$ & $99 \pm 13$ & $\mathbf{0 . 0 3 9}$ \\
PD20meth & $495 \pm 55$ & $424 \pm 99$ & 0.549 \\
\hline
\end{tabular}

Notes: All values are expressed as mean \pm SD, unless otherwise stated. Bold represents statistically significant values $(p<0.05)$.

Abbreviations: $\mathrm{FEV}_{1}$, forced expiratory volume in I second; FVC, forced vital capacity; $\mathrm{FEF}_{25-75}$, forced expiratory flow $25 \%-75 \%$; $\mathrm{FRC}$, functional residual capacity; TLC, total lung capacity; RV, residual volume; KCO, CO transfer coefficient; $\mathrm{PD} 20$ meth, provocative dose of methacholine producing a $20 \%$ fall in $\mathrm{FEV}$.

Table 3 Total and differential cell counts in sputum and BALF

\begin{tabular}{llll}
\hline & Off-season & Post exposure & p-value \\
\hline Induced sputum & & & \\
Total no. of cells $\times 10^{4}$ & $23 \pm 4$ & $42 \pm 6$ & 0.624 \\
Macrophage\% & $32 \pm 5$ & $41 \pm 6$ & 0.749 \\
Neutrophils\% & $16 \pm 4$ & $48 \pm 5$ & $\mathbf{0 . 0 3 5}$ \\
Eosinophils\% & $1.8 \pm 0.7$ & $3 \pm 0.8$ & $\mathbf{0 . 0 5}$ \\
Lymphocytes\% & $13.5 \pm 2$ & $19 \pm 6$ & 0.637 \\
BALF & & & \\
Total no. of cells $\times 10^{4}$ & $19 \pm 4$ & $30 \pm 5$ & 0.219 \\
Macrophage\% & $81 \pm 2$ & $83 \pm 3$ & 0.629 \\
Neutrophils\% & $2 \pm 0.3$ & $4 \pm 1.2$ & $\mathbf{0 . 0 4 3}$ \\
Eosinophils\% & $0.58 \pm 0.13$ & $2.4 \pm 1.2$ & $\mathbf{0 . 0 5}$ \\
Lymphocytes\% & $13 \pm 2$ & $15 \pm 2$ & 0.930 \\
\hline Notes: All vat
\end{tabular}

Notes: All values are expressed as mean $\pm \mathrm{SE}$, unless otherwise stated. Bold represents statistically significant values $(p<0.05)$.

Abbreviations: BALF, bronchoalveolar lavage fluid; SE, standard error. to off-season $(4 \pm 1.2 \%$ vs $2 \pm 0.3 \%$ [mean $\pm \mathrm{SE}$ ], $p=0.043$; Table 3). There were no significant differences in the rest of the cell types assessed off-season and post exposure (Table 3 ).

IL-8 and TNF- $\alpha$ levels were found to be statistically significantly higher in the sputum supernatants post exposure as compared to the off-season ( $p=0.03$ and $p=0.04$, respectively; Figure 1). Furthermore, serum IL-8, VEGF, and TNF- $\alpha$ levels were statistically significantly higher post exposure as compared to off-season ( $p=0.03, p=0.02$, and $p=0.03$, respectively; Figure 2). There were no differences in the degree of inflammation induced post exposure or off-season between smoking and nonsmoking firefighters (Table 4). We postulate that the reason for these results, especially for off-season, may be explained by the small number of smokers (eight people) and the rather low number of smoking pack-years.

In firefighters who participated in the operations of forest firefighting continuously for $>10$ hours $(38 \pm 22$ hours [mean \pm $\mathrm{SD}]$ ), the exposure induced a more intense systemic inflammation compared to an exposure of $<10$ hours $(6 \pm 3$ hours $[$ mean $\pm \mathrm{SD}]$; Figure 3).

\section{Discussion}

In the current study on forest firefighters, a measurable eosinophilic and neutrophilic inflammation was shown to be induced in the bronchial airways after acute exposure in forest firefighting. This was associated with respiratory symptoms from the upper and lower respiratory tract and pulmonary function impairment. Additionally, a measurable systemic inflammatory response was demonstrated.

After the World Trade Center incident, a number of studies assessed the effects of occupational exposure on respiratory symptoms and pulmonary function in professional firefighters. ${ }^{3,9,17,18,24}$ However, most of these studies examined the long-term consequences of inhalation of particulate matter and irritant gases on pulmonary function and airway and systemic inflammation.

The most striking finding of our study is the significantly higher percentage of eosinophils post exposure compared to off-season in the sputum and BAL of firefighters. Firefighters are exposed to numerous irritants during the operations, and such an exposure alters lung permeability easing the penetration and accessibility of inhaled allergens, leading eventually to an allergic immune response. ${ }^{25,26}$ Allergic airway sensitization has been previously reported among firefighters on the basis of the presence of atopy and symptoms from the upper and lower respiratory systems. ${ }^{4,5,9,13}$ We recently documented allergic sensitization in professional firefighters after chronic occupational exposure. ${ }^{13}$ Furthermore, eosinophilia has been 


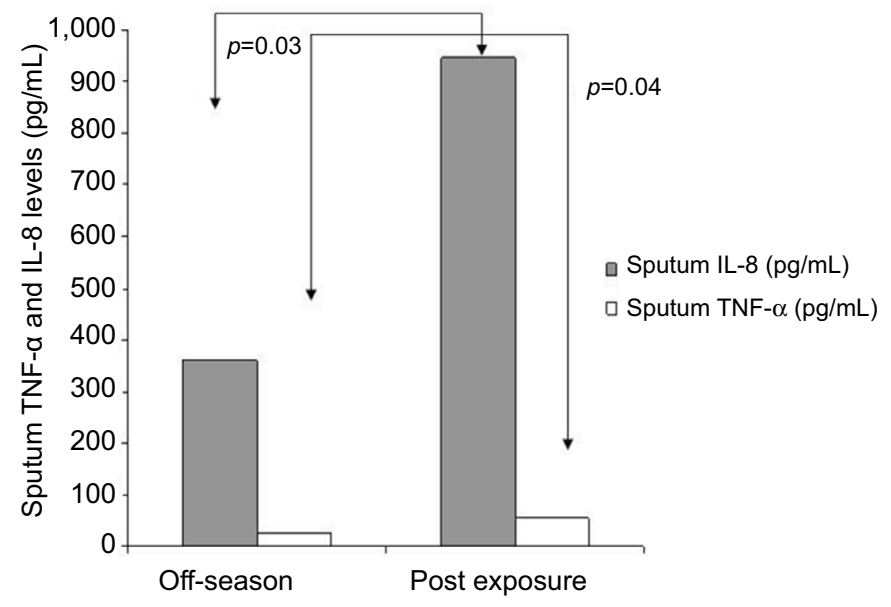

Figure I Sputum levels of TNF- $\alpha$ and IL-8 off-season and post exposure.

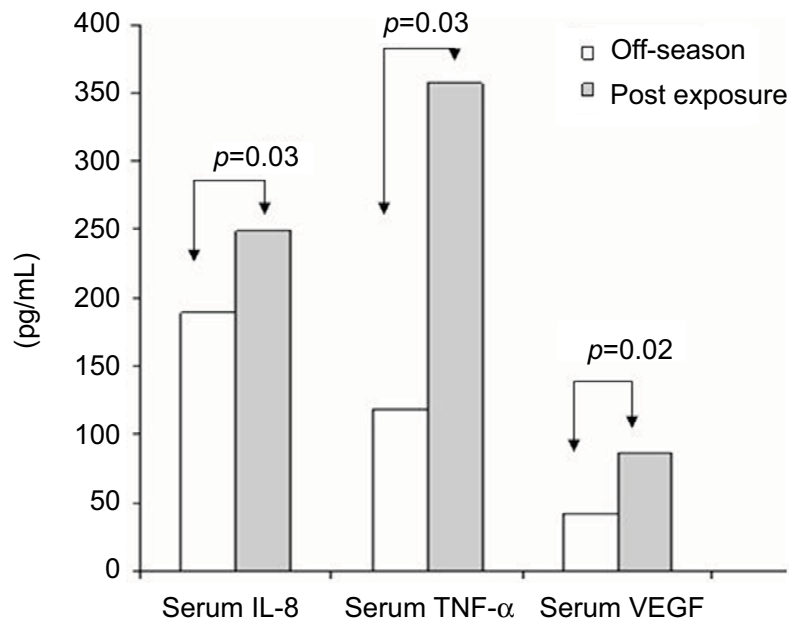

Figure 2 Serum levels of TNF- $\alpha$, VEGF, and IL-8 off-season and post exposure.

shown in the induced sputum of sensitized asthmatics and in asbestos workers ${ }^{27}$ after chronic occupational exposure. In the current study, we demonstrated an induction of the allergic immune response in the airways after firefighting. Combined with our and others' previous findings on the effects of chronic exposure on the airways, we would be justified to suggest that repetitive exposure to combustion products in combination with allergens may lead to the allergic sensitization seen in professional firefighters after long-term exposure. ${ }^{4,12,13,28}$ Indeed, a high risk for asthma and allergic rhinosinusitis is reported among professional firefighters in numerous studies ${ }^{29-32} \mathrm{~A}$ significantly higher allergen-specific $\mathrm{IgE}$ induction compared to the challenge with the allergen alone has been previously demonstrated in the work of Dong et $\mathrm{l}^{33}$ who demonstrated that exposure to diesel exhaust particles prior to ovalbumin sensitization in rats exacerbates the
Table 4 Markers of inflammation in induced sputum and serum

\begin{tabular}{llll}
\hline Marker & Off-season & Post exposure & p-value \\
\hline Sputum IL-4 $(\mathrm{pg} / \mathrm{mL})$ & $4(3-38)$ & $5(3-47)$ & 0.4 \\
Sputum IL-I3 $(\mathrm{pg} / \mathrm{mL})$ & $188(175-1322)$ & $195(178-1405)$ & 0.3 \\
Sputum VEGF $(\mathrm{pg} / \mathrm{mL})$ & $198(5-325)$ & $204(8-368)$ & 0.83 \\
Sputum ECP $(\mathrm{pg} / \mathrm{mL})$ & $44(4-91)$ & $56(6-98)$ & 0.97 \\
Serum IL-4 $(\mathrm{pg} / \mathrm{mL})$ & $7(6-28)$ & $9(6-48)$ & 0.24 \\
Serum IL-I3 $(\mathrm{pg} / \mathrm{mL})$ & $380(307-453)$ & $390(327-530)$ & 0.27 \\
Serum ECP $(\mathrm{pg} / \mathrm{mL})$ & $19(15-45)$ & $21(15-118)$ & 0.97 \\
\hline
\end{tabular}

Note: Values are expressed as median (interquartile range).

Abbreviations: IL, interleukin; VEGF, vascular endothelial growth factor; ECP, eosinophilic cationic protein.

allergic responses to the subsequent challenge with OVA in OVA-sensitized rats. Furthermore, increased sensitization to outdoor allergens ${ }^{34,35}$ has been documented in people living in areas with high traffic.

It is well established that occupational exposure in firefighters leads to chronic airway and systemic inflammation, and we have recently demonstrated that this is evident even from the first year in occupation, becoming more intense as the exposure years increase. ${ }^{7,13-16}$ In this study, it was further shown that acute exposure during forest firefighting significantly augments the intensity of airway and systemic inflammation compared to the baseline inflammatory background. A markedly higher degree of airway inflammation was documented post exposure compared to off-season as reflected by the higher number of total cells and the elevated counts of neutrophils in sputum and BAL. This is in line with the results of studies examining the acute effect of inhalation of particulate matter or diesel exhaust showing increased neutrophil counts in BAL and induced sputum following exposure. ${ }^{15,36-38}$ Specifically, Greven et al ${ }^{15}$ showed that acute 


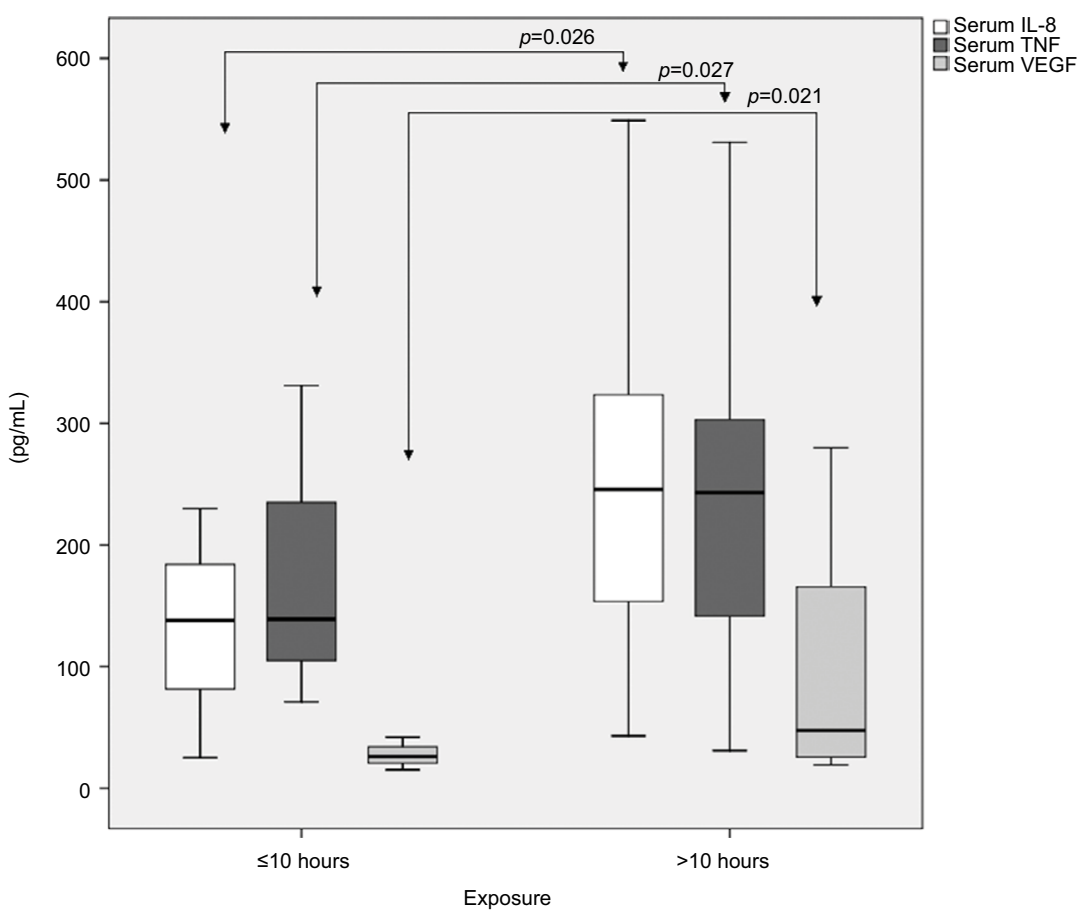

Figure 3 Time-dependent induction of systemic inflammation in forest firefighters with continuous exposure.

exposure to fire smoke induces acute neutrophilic airway and long-lasting systemic inflammation in healthy firefighters, and this was also shown in our recent work on professional firefighters. ${ }^{13}$ Additionally, significantly higher levels of IL-8 and TNF- $\alpha$ were found in induced sputum post exposure. Holgate et a $l^{39}$ demonstrated that modest concentrations of diesel exhaust have clear-cut inflammatory effects on the airways of non-asthmatic subjects, suggesting a direct effect of diesel exhaust on IL-8 production, leading to upregulation of endothelial adhesion molecules and neutrophil recruitment. In this study, we documented that acute exposure further enhances that long-lasting systemic inflammation, and this effect is time dependent. There were no differences in the degree of inflammation induced post exposure or off-season between smoking and nonsmoking firefighters. We postulate that the reason for these results, especially for off-season, may be explained by the small number of smokers (eight people) and the rather low number of smoking pack-years.

Serum IL-8, VEGF, and TNF- $\alpha$ concentrations were found to be significantly higher post exposure compared to off-season. The elevated levels of circulating cytokines following smoke exposure are consistent with the findings of previous studies indicating the stimulation of the bone marrow $^{40-42}$ and the initiation of a systemic inflammatory response as a result of smoke inhalation. IL-8 is a potent stimulator of bone marrow promoting the sequestration of neutrophils in the lung. ${ }^{43}$ This possibly enhances or perpetuates the neutrophilic inflammation seen in the bronchi and initiates the systemic inflammatory response as a result of smoke inhalation.

Exposure to products of pyrolysis has been shown to increase airway responsiveness in some subjects., ${ }^{40,11,18,44}$ Although we observed no increase in bronchial hyperreactivity, this may not be odd since bronchial hyperreactivity is defined by and dependent on multiple factors. In most studies, bronchial hyperreactivity after smoke inhalation seems to be related to a prior long history of firefighting activity, the number of fires fought in 12 months, the atopic condition, and the respiratory protection devices used. ${ }^{3}$ In the relatively small sample studied here, the diversities between the subjects may justify the lack of bronchial hyperreactivity seen post exposure.

Our results are in agreement with previous studies showing deterioration in pulmonary function after exposure. ${ }^{6-8,44}$ We specifically found a larger decrease in $\mathrm{FEF}_{25-75}$, a measure of smaller airway dysfunction, suggesting that acute exposure to smoke during firefighting mainly affects peripheral lung. This finding agrees with the early findings of Large et $\mathrm{al}^{7}$ who showed a significant decrease in spirometric values right after exposure, Greven et $\mathrm{a}^{44}$ who showed a significant decrease in spirometric values right after exposure and 24 hours later, Slaughter et $\mathrm{al}^{6}$ who showed a greater decrease in $\mathrm{FEF}_{25-75}$ post shift compared to pre shift, and Liu et $\mathrm{a}^{45}$ 
who compared cross-season effects of forest fire smoke on lung function. Symptoms from both the upper and the lower respiratory tract included chest tightness, wheezing, cough, increased sputum production, and sneezing, and they were more pronounced after exposure to smoke compared to offseason. Previous studies observed a significant increase in eye irritation, nose irritation, cough, phlegm, and wheezing from preseason to late season, with strong associations noted for recent firefighting activity. ${ }^{5,30}$

\section{Conclusion}

This study showed that each exposure to smoke and allergens during forest firefighting significantly augments the intensity of airway and systemic inflammation in relation to the baseline inflammatory background due to chronic exposure. Interestingly, an eosinophilic immune response is induced in the airways, which is suggested to eventually lead to allergic airway sensitization and increased incidence of rhinitis and asthma after prolonged exposure. It seems that at every single exposure, an airway and systemic inflammatory spike is induced, eventually leading to the establishment of pathology. These findings underline the need for the SCBA use during firefighting.

\section{Acknowledgments}

The authors would like to thank the firefighters of the Hellenic Fireforce Department for their participation in this study and the nurses L. Stoubi and F. Zikopoulou for their valuable assistance and support in the endoscopic laboratory. The study was supported by “Thorax" Foundation and funded by Chiesi Hellas.

\section{Disclosure}

The authors report no conflicts of interest in this work.

\section{References}

1. Reinhardt TE, Ottmar RD. Baseline measurements of smoke exposure among wildland firefighters. J Occup Environ Hyg. 2004;1(9): 593-606.

2. Baxter CS, Hoffman JD, Knipp MJ, Reponen T, Haynes EN. Exposure of firefighters to particulates and polycyclic aromatic hydrocarbons. J Occup Environ Hyg. 2014;11(7):D85-D91.

3. Feldman DM, Baron SL, Bernard BP, et al. Symptoms, respirator use, and pulmonary function changes among New York City firefighters responding to the World Trade Center disaster. Chest. 2004;125(4):1256-1264.

4. Miedinger D, Chhajed PN, Stolz D, et al. Respiratory symptoms, atopy and bronchial hyperreactivity in professional firefighters. Eur Respir J. 2007;30(3):538-544.

5. Gaughan DM, Cox-Ganser JM, Enright PL, et al. Acute upper and lower respiratory effects in wildland firefighters. J Occup Environ Med. 2008;50(9):1019-1028.
6. Slaughter JC, Koenig JQ, Reinhardt TE. Association between lung function and exposure to smoke among firefighters at prescribed burns. J Occup Environ Hyg. 2004;1(1):45-49.

7. Large AA, Owens GR, Hoffman LA. The short-term effects of smoke exposure on the pulmonary function of firefighters. Chest. 1990;97(4):806-809.

8. Jacquin L, Michelet P, Brocq FX, et al. Short-term spirometric changes in wildland firefighters. Am J Ind Med. 2011;54(11):819-825.

9. Prezant DJ, Weiden M, Banauch GI, et al. Cough and bronchial responsiveness in firefighters at the World Trade Center site. $N$ Engl J Med. 2002;347(11):806-815.

10. Chia KS, Jeyaratnam J, Chan TB, Lim TK. Airway responsiveness of firefighters after smoke exposure. Br J Ind Med. 1990;47(8):524-527.

11. Sherman CB, Barnhart S, Miller MF, et al. Firefighting acutely increases airway responsiveness. Am Rev Respir Dis. 1989;140(1):185-190.

12. Wyler C, Braun-Fahrländer C, Künzli N, et al. Exposure to motor vehicle traffic and allergic sensitization. The Swiss Study on Air Pollution and Lung Diseases in Adults (SAPALDIA) Team. Epidemiology. 2000;11(4):450-456.

13. Gianniou N, Katsaounou P, Dima E, et al. Prolonged occupational exposure leads to allergic airway sensitization and chronic airway and systemic inflammation in professional firefighters. Respir Med. 2016;118:7-14.

14. Swiston JR, Davidson W, Attridge S, Li GT, Brauer M, van Eeden SF. Wood smoke exposure induces a pulmonary and systemic inflammatory response in firefighters. Eur Respir J. 2008;32(1):129-138.

15. Greven FE, Krop EJ, Spithoven JJ, et al. Acute respiratory effects in firefighters. Am J Ind Med. 2012;55(1):54-62.

16. Hejl AM, Adetona O, Diaz-Sanchez D, et al. Inflammatory effects of woodsmoke exposure among wildland firefighters working at prescribed burns at the Savannah River Site, SC. J Occup Environ Hyg. 2013;10(4):173-180.

17. Banauch GI, Hall C, Weiden M, et al. Pulmonary function after exposure to the World Trade Center collapse in the New York City Fire Department. Am J Respir Crit Care Med. 2006;174(3):312-319.

18. Banauch GI, Alleyne D, Sanchez R, et al. Persistent hyperreactivity and reactive airway dysfunction in firefighters at the World Trade Center. Am J Respir Crit Care Med. 2003;168(1):54-62.

19. American Thoracic Society. Standardization of spirometry, 1994 update. Am J Respir Crit Care Med. 1995;152:1107e36.

20. Crapo RO, Casaburi R, Coates AL, et al. Guidelines for methacholine and exercise challenge testing-1999. This official statement of the American Thoracic Society was adopted by the ATS Board of Directors, July 1999. Am J Respir Crit Care Med. 2000;161(1):309-329.

21. Rovina N, Dima E, Gerassimou C, Kollintza A, Gratziou C, Roussos C. IL-18 in induced sputum and airway hyperresponsiveness in mild asthmatics: effect of smoking. Respir Med. 2009;103(12):1919-1925.

22. Kips JC, Fahy JV, Hargreave FE, et al. Methods for sputum induction and analysis of induced sputum: a method for assessing airway inflammation in asthma. Eur Respir J Suppl. 1998;26:9e12S.

23. Baughman RP. Technical aspects of bronchoalveolar lavage: recommendations for a standard procedure. Semin Respir Crit Care Med. 2007;28(5):475-485.

24. Herbert R, Moline J, Skloot G, et al. The World Trade Center disaster and the health of workers: five-year assessment of a unique medical screening program. Environ Health Perspect. 2006;114(12):1853-1858.

25. D'Amato G, Liccardi G, D'Amato M, Holgate S. Environmental risk factors and allergic bronchial asthma. Clin Exp Allergy. 2005;35:1113-1124.

26. Devalia JL, Rusznak C, Davies RJ. Allergen/irritant interaction - its role in sensitization and allergic disease. Allergy. 1998;53:335-345.

27. Maestrelli P, Calcagni PG, Saetta M, et al. Sputum eosinophilia after asthmatic responses induced by isocyanates in sensitized subjects. Clin Exp Allergy. 1994;24(1):29-34.

28. Diaz-Sanchez D, Penichet-Garcia M, Saxon A. Diesel exhaust particles directly induce activated mast cells to degranulate and increase histamine levels and symptom severity. J Allergy Clin Immunol. 2000;106(6):1140-1146. 
29. Niles JK, Webber MP, Liu X, et al. The upper respiratory pyramid: early factors and later treatment utilization in World Trade Center exposed firefighters. Am J Ind Med. 2014;57(8):857-865.

30. Niles JK, Webber MP, Cohen HW, et al. The respiratory pyramid: From symptoms to disease in World Trade Center exposed firefighters. Am J Ind Med. 2013;56(8):870-880.

31. Ribeiro M, de Paula Santos U, Bussacos MA, Terra-Filho M. Prevalence and risk of asthma symptoms among firefighters in São Paulo, Brazil: a population-based study. Am J Ind Med. 2009;52(3):261-269.

32. Weakley J, Webber MP, Gustave J, et al. Trends in respiratory diagnoses and symptoms of firefighters exposed to the World Trade Center disaster: 2005-2010. Prev Med. 2011;53(6):364-369.

33. Dong CC, Yin XJ, Ma JY, et al. Effect of diesel exhaust particles on allergic reactions and airway responsiveness in ovalbumin-sensitized brown Norway rats. Toxicol Sci. 2005;88(1):202-212.

34. Gruzieva O, Bellander T, Eneroth K, et al. Traffic-related air pollution and development of allergic sensitization in children during the first 8 years of life. J Allergy Clin Immunol. 2012;129(1):240-246.

35. Bernstein DI. Traffic-related pollutants and wheezing in children. J Asthma. 2012;49(1):5-7.

36. Salvi SS, Nordenhall C, Blomberg A, et al. Acute exposure to diesel exhaust increases IL-8 and GRO-alpha production in healthy human airways. Am J Respir Crit Care Med. 2000;161(2 Pt 1):550-557.

37. Fujii T, Hayashi S, Hogg JC, Vincent R, Van Eeden SF. Particulate matter induces cytokine expression in human bronchial epithelial cells. Am J Respir Cell Mol Biol. 2001;25(3):265-271.
38. Ishii H, Hayashi S, Hogg JC, et al. Alveolar macrophage-epithelial cell interaction following exposure to atmospheric particles induces the release of mediators involved in monocyte mobilization and recruitment. Respir Res. 2005;6:87.

39. Holgate ST, Sandström T, Frew AJ, et al. Health effects of acute exposure to air pollution. Part I: healthy and asthmatic subjects exposed to diesel exhaust. Res Rep Health Eff Inst. 2003;112:1-30. discussion 51-67.

40. Tan WC, Qiu D, Liam BL, et al. The human bone marrow response to acute air pollution caused by forest fires. Am J Respir Crit Care Med. 2000;161(4 pt 1):1213-1217.

41. Goto Y, Ishii H, Hogg JC, et al. Particulate matter air pollution stimulates monocyte release from the bone marrow. Am J Respir Crit Care Med. 2004;170(8):891-897.

42. Terashima T, Wiggs B, English D, Hogg JC, van Eeden SF. Phagocytosis of small carbon particles (PM10) by alveolar macrophages stimulates the release of polymorphonuclear leukocytes from bone marrow. Am J Respir Crit Care Med. 1997;155(4):1441-1447.

43. Terashima T, English D, Hogg JC, van Eeden SF. Release of polymorphonuclear leukocytes from the bone marrow by interleukin-8. Blood. 1998;92(3):1062-1069.

44. Greven F, Krop E, Spithoven J, Rooyackers J, Kerstjens H, Heederik D. Lung function, bronchial hyperresponsiveness, and atopy among firefighters. Scand J Work Environ Health. 2011;37(4):325-331.

45. Liu D, Tager IB, Balmes JR, Harrison RJ. The effect of smoke inhalation on lung function and airway responsiveness in wildland fire fighters. Am Rev Respir Dis. 1992;146(6):1469-1473.
Journal of Asthma and Allergy

\section{Publish your work in this journal}

The Journal of Asthma and Allergy is an international, peer-reviewed open access journal publishing original research, reports, editorials and commentaries on the following topics: Asthma; Pulmonary physiology; Asthma related clinical health; Clinical immunology and the immunological basis of disease; Pharmacological interventions and
Dovepress

new therapies. This journal is included in PubMed. The manuscript management system is completely online and includes a very quick and fair peer-review system, which is all easy to use. Visit http://www. dovepress.com/testimonials.php to read real quotes from published authors.

Submit your manuscript here: https://www.dovepress.com/journal-of-asthma-and-allergy-journal 